\title{
A Community-Based, Cross-Sectional Study Assessing the Level of Awareness and Insight Related to Cardiovascular Diseases
}

\author{
Ali S. Alghamdi ${ }^{1}$, Muhanad S. Alzahrani ${ }^{2}$, Basel M. Alsolami ${ }^{2}$, Salman A. Thabet ${ }^{2}$, Basel S. Alghamdi ${ }^{2}$, \\ Abdulhalim J. Kinsara ${ }^{3}$ \\ 1. Internal Medicine, College of Medicine-Western Region, King Abdullah International Medical Research Center, King \\ Saud Bin Abdulaziz University for Health Sciences, Ministry of National Guard Health Affairs, Jeddah, SAU 2. Internal \\ Medicine, College of Medicine-Western Region, King Saud Bin Abdulaziz University for Health Sciences, Jeddah, SAU 3. \\ Cardiology, College of Medicine-Western Region, King Abdullah International Medical Research Center, King Saud Bin \\ Abdulaziz University for Health Sciences, Ministry of National Guard Health Affairs, Jeddah, SAU
}

Corresponding author: Ali S. Alghamdi, ali.alhamdan23@gmail.com

\section{Abstract \\ Objective}

The disease outcome had been shown to improve with improving patient knowledge. The study had two objectives, firstly to assess the level of knowledge about cardiovascular diseases (CVDs) in the general population, and secondly, to provide written educational material regarding the risk factors, major symptoms, and the prevention of CVDs.

\section{Method}

The target population was the residents living in the Western region of Saudi Arabia, aged 18 years and above. All were invited to participate voluntarily. A pre-structured questionnaire was designed to collect data related to age, gender, marital status, education level, occupation, lifestyle habits, and a history of heart diseases, as well as cardiac symptoms, and risk factors. The educational material was provided after the questionnaire.

\section{Results}

The majority of the participants were female (74.8\%). The risk factors most frequently identified were lack of exercise, stress, and obesity. Chest pain was recognized as a major symptom (87.6\%). Other symptoms included dyspnea, syncope, and excessive sweating. The level of knowledge regarding the risk factors for cardiovascular disease was poor. Only $18.5 \%$ were knowledgeable about the risk factors. The majority (60\%) could identify the preventable factors, including smoking cessation (92.2\%), a high level of cholesterol (88.6\%), and hypertension (78.7\%). The majority (83.7\%) read the educational material and $99 \%$ reported that the lecture increased their knowledge about cardiovascular disease.

Review began 05/26/2021 Review ended 06/04/2021 Published 06/16/2021

\section{Copyright 2021}

Alghamdi et al. This is an open access article distributed under the terms of the Creative Commons Attribution License CC-BY 4.0., which permits unrestricted use, distribution, and reproduction in any medium, provided the original author and source are credited.

\section{Conclusion}

Although cardiovascular risk factors are common, there is a big gap in the knowledge in our population. Further, alarming symptoms that bring the patients to medical care are also deficient. A call for action at different levels is urgent. Simple educational material in a basic language and virtual education are useful and cheap tools that must be practiced wherever possible. Education is welcomed by the participants.

Categories: Cardiology, Internal Medicine, Medical Education

Keywords: insight, awareness, cardio vascular disease, saudi population, education, prevention

\section{Introduction}

Cardiovascular diseases (CVDs) are the leading cause of death globally, with an estimated 17.9 million deaths annually. Four of five deaths are due to myocardial infarction and stroke, and one-third of these deaths occur prematurely in people under the age of 70 years [1]. The mean age for developing coronary artery disease (CAD) in the Middle East is 10 years younger than the mean age in Western countries [2]. A substantial increase in the prevalence of CVDs' risk factors in the Middle East has been reported [3], and the prevalence of CAD-related risk factors in Saudi patients with established CAD is concerning [4-5]. Improved knowledge about the disease may result in an earlier presentation to medical care and better patient outcomes. Individuals need to know and understand the implications of CVD, its symptoms, and risk factors to enable proactive minimizing of risk [6]. However, risk factors may vary between different regions and ethnicities [7,8]. A study from Eastern Saudi Arabia reported that only 3\% were aware of a history of CVDs [9]. There is no literature related to the level of CVD knowledge in the Western region of Saudi Arabia. In addition, we included educational material to raise the level of CVD knowledge in the study population. 


\section{Materials And Methods}

Study setting and participants: The design was a community-based cross-sectional study. Residents, residing in the Western region of Saudi Arabia, aged 18 years and older were invited to participate voluntarily. A prestructured questionnaire was used to collect the data. The sample was calculated as 385 using the Raosoft Online Software (Raosoft, Inc., Seattle, WA, USA) [10]. The margin of error was $5 \%$, with a $95 \%$ confidence level. The population size is approximately 10 million. Due to the possibility of incomplete responses, the sample was increased by $15 \%$ to 443 .

Study variables: The questionnaire was previously validated $[9,11]$. The online questionnaire included `six sections. The first section gathered demographic characteristics. The second section contained items exploring medical illnesses known to result in CVD: diabetes, hypertension, hypertriglyceridemia, hypercholesterolemia, smoking, and medication history. The third section focused on the risk factors for CVD, and the fourth section assessed the participants' level of knowledge of CVD symptoms. The fifth section measured the level of knowledge regarding normal levels required to prevent CVD incidence for HbA1C, blood pressure and cholesterol, and smoking cessation). The last section contained educational material developed by the authors, followed by two questions to assess the benefit, and the perceived increase in the level of knowledge.

Statistical methods and ethical considerations: The categorical variables are presented as frequency and percentage, and the continuous variables as mean \pm SD. The statistical tests used included a non-parametric Mann-Whitney U test to compare the differences between two independent groups, such as gender, should the dependent variable be ordinal or continuous, but not normally distributed. A non-parametric KruskalWallis test was used for variables categorized in more than two groups, instead of the ANOVA. A nonparametric, related-samples Friedman test was used for variables categorized into more than two related groups. The knowledge levels were categorized as excellent (90 and above), very good (80-89), good (70-79), acceptable (60-69), and weak (below 60). The analysis was done with SPSS version 25 . The study was approved by the Institutional Review Board of King Abdullah International Medical Research Center, SP20/348/J. The participants signed a consent form, indicating that participation was voluntary. No names or personal data were collected. The data were saved in a workplace computer to maintain confidentiality.

\section{Results}

The study included 460 participants. The majority (74.8\%) were female, $94.3 \%$ were Saudi, and $51.1 \%$ were married. The distribution of the age categories were $15.3 \%<20 \mathrm{~s}, 32.4 \% 20$-29 years; $9.6 \% 30-39$ years, $23.3 \%$ 40-49 years, and $19.4 \% 50$ years and above. The majority (69.7\%) were university graduates, with $24.6 \%$ secondary school graduates (24.6\%). Less than half (41.1\%) were employed. The highest proportion (37\%) had a normal weight, with a mean BMI of $25.9 \pm 6.5 \mathrm{~kg} / \mathrm{m}^{2}$. A quarter (25.2\%) smoked, with a mean of $9.6 \pm$ 8.8 years. The most frequent comorbidities were hypercholesterolemia (15.4\%), hypertension (11.7\%), diabetes (11.5\%), and a history of CVD (7\%) (Table 1). 


\section{Cureus}

\begin{tabular}{|c|c|c|}
\hline & Characteristics & Count (\%) \\
\hline \multirow{5}{*}{ Age categories (years) } & Below 20 & $70(15.3)$ \\
\hline & $20-29$ & $149(32.4)$ \\
\hline & $30-39$ & $44(9.6)$ \\
\hline & $40-49$ & $107(23.3)$ \\
\hline & $50+$ & $89(19.4)$ \\
\hline \multirow{7}{*}{ Level of education } & Primary & $6(1.3)$ \\
\hline & Intermediate & $10(2.2)$ \\
\hline & Secondary & $113(24.6)$ \\
\hline & University & $321(69.7)$ \\
\hline & Diploma & $4(0.9)$ \\
\hline & Masters & $3(0.7)$ \\
\hline & Other & $3(0.7)$ \\
\hline \multirow{4}{*}{ Income } & Less than 5,000 SAR & $225(48.9)$ \\
\hline & $5,000-10,000$ SAR & $84(18.3)$ \\
\hline & $10,001-15,000$ SAR & $74(16.1)$ \\
\hline & More than 15,000 SAR & $77(16.7)$ \\
\hline \multirow{5}{*}{ BMI (kg/m²) } & Mean \pm SD & $25.9 \pm 6.5$ \\
\hline & Underweight & $54(11.8)$ \\
\hline & Normal & $170(37)$ \\
\hline & Overweight & $126(27.5)$ \\
\hline & Obese & $109(23.7)$ \\
\hline
\end{tabular}

TABLE 1: Demographic characteristics of the sample.

There was a significant association between gender and CVD, with female dominance ( $\mathrm{p}$-value $=0.037$ ). In terms of marital status, singles were more likely to have CVD ( $\mathrm{p}$-value $=0.013$ ). Regarding age, there was a statistically significant association between the older age categories and CVD $(p$-value $=0.001)$. There was also a significant association between smoking and CVD ( $\mathrm{p}$-value $=<0.001)$ (Table 2). 


\section{Cureus}

\begin{tabular}{|c|c|c|c|}
\hline & Characteristics & Count (\%) & P-value \\
\hline \multirow[t]{3}{*}{ Gender } & Male & $13(40.6)$ & $0.037^{*}$ \\
\hline & Below 20 & $4(12.5)$ & \\
\hline & $20-29$ & $5(15.6)$ & \\
\hline \multirow[t]{3}{*}{ Age categories } & $30-39$ & $0(0)$ & $<0.001^{\star \star}$ \\
\hline & $40-49$ & 4 (12.5) & \\
\hline & $50+$ & $19(39.4)$ & \\
\hline
\end{tabular}

TABLE 2: Age and sex association with cardiovascular disease.

* - Significant

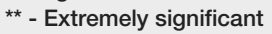

The majority (80\%) indicated lack of exercise, stress, and obesity as the most important risk factors. The mean overall knowledge score was $66.5 \pm 23.8 \%$. The majority (87.6\%) listed chest pain or discomfort as symptoms, and the overall CVD knowledge score was $55.1 \pm 17.5 \%$. Regarding preventive methods, the majority $(92.2 \%)$ considered smoking cessation as essential, a normal cholesterol level (88.3\%), normal blood pressure (78.7\%), and 75.9\% a normal HbA1C level $<7$ (Tables 3 and 4 ).

\begin{tabular}{|l|l|}
\hline Factors & Count (\%) \\
\hline Chest pain or discomfort & $403(87.6)$ \\
\hline Cheat pain that radiates to the left arm & $397(86.3)$ \\
Shortness of breath & $386(83.9)$ \\
\hline Feeling weak, light-headed, or faint & $371(80.7)$ \\
\hline Pain or numbness in the arm & $357(77.6)$ \\
\hline Loss of consciousness & $332(72.2)$ \\
\hline Excessive sweating & $247(53.7)$ \\
\hline The pain increased with exertion & $244(53)$ \\
\hline Pain in the neck, jaw, or back & $206(44.8)$ \\
\hline Fast heartbeats after high-intensity exercises & $178(38.7)$ \\
\hline Pain relieved with rest or nitroglycerin & $153(33.3)$ \\
\hline Abdominal pain & $44(9.6)$ \\
\hline Overall knowledge (Mean \pm SD) in \% & $55.1 \pm 17.5$ \\
\hline
\end{tabular}

TABLE 3: The sample's level of awareness and insight related to cardiovascular disease symptoms. 


\section{Cureus}

\begin{tabular}{|l|l}
\hline Factors & Count (\%) \\
\hline Lack of exercise & $416(90.4)$ \\
Stress & $392(85.2)$ \\
Obesity & $379(82.4)$ \\
Hypertension & $354(77)$ \\
Current/Recent smoker (<1 year) & $346(75.2)$ \\
Family history of cardiovascular diseases & $339(73.7)$ \\
Unhealthy diet & $331(72)$ \\
Previous heart attack & $324(70.4)$ \\
High level of LDL Cholesterol & $365(79.3)$ \\
Smoking increases the risk of cardiovascular disease & $311(67.6)$ \\
Age & $299(65)$ \\
Cerebrovascular disease & $270(58.7)$ \\
Diabetes & $259(56.3)$ \\
Chronic kidney disease & $194(42.2)$ \\
Overall knowledge (Mean \pm SD) in \% & $66.5 \pm 23.8$
\end{tabular}

TABLE 4: Degree of awareness of different risk factors contributing to cardiovascular disease.

LDL: Low-density lipoprotein.

The level of knowledge was classified into five groups depending on the correct responses: excellent (90 and above), very good (80-89), good (70-79), acceptable (60-69), and weak (below 60). The highest proportion $(30.4 \%, \mathrm{n}=140)$ was in the weak knowledge group, $23.7 \%(\mathrm{n}=109)$ in the good knowledge group, $18.5 \%(\mathrm{n}=$ $85)$ in the excellent knowledge group, $14.1(n=65)$ in the acceptable knowledge group, and $13.3 \%(n=61)$ in the very good group $(\mathrm{p}$-value $=0.001)$. The majority $(58.5 \%, \mathrm{n}=269)$ had weak knowledge about the

symptoms of cardiovascular disease, $20 \%$ good knowledge, and $19.3 \%$ acceptable knowledge. Only $2.3 \%$ ( $=$ 10 ) were in the very good knowledge group. The sample's level of knowledge regarding the factors that prevent CVD was mostly excellent (60\%), good (23.9\%), and weak (16.1\%) (Table 5).

\begin{tabular}{|c|c|c|c|c|c|c|}
\hline Knowledge level & Excellent n (\%) & Very good n (\%) & Good n (\%) & Acceptable n (\%) & Weak n (\%) & P-value \\
\hline CVD risk factors & 85 (18.5) & $61(13.3)$ & $109(23.7)$ & $65(14.1)$ & $140(30.4)$ & $<0.001^{\star \star}$ \\
\hline CVD symptoms & $4(0,9)$ & $6(1.3)$ & $92(20)$ & 89 (19.3) & 269 (58.5) & $<0.001^{\star \star}$ \\
\hline CVD preventive factors & $276(60)$ & $0(0)$ & $110(23.9)$ & $0(0)$ & $74(16.1)$ & $<0.001^{\star \star}$ \\
\hline
\end{tabular}

TABLE 5: The assessment level of the sample towards risk factors, symptoms, and preventive factors of cardiovascular disease.

** - Extremely significant

A third (32\%) of the sample was diagnosed with CVD: heart failure (28\%), coronary heart [ASAA1] disease (25\%), congenital heart disease (16\%), arrhythmia (13\%), and other diseases (19\%). Of this group, only $65.6 \%$ were taking medication. The most frequently used cardiac medication were anticoagulation (47.6\%), beta-blockers, and diuretics (38.1\%), and only $4.8 \%$ were prescribed angiotensin-converting enzyme inhibitors (ACEIs). 


\section{Discussion}

This is the first study conducted in the Western region of Saudi Arabia, assessing the level of knowledge related to CVD risk factors, signs and symptoms, and preventive factors, in addition to providing educational material to the general population. The knowledge deficit that diabetes and chronic kidney disease were not considered as serious factors in causing CVD might explain the high prevalence and lack of control of these two risks. Similar findings were reported with a negative dietary intake being the highest risk factor, and only $12 \%, 26 \%$, and $39 \%$ of the sample indicated that diabetes mellitus, smoking, and lack of physical activity were risk factors for CVD, respectively [2]. Although most participants were familiar with the most known CVD risk factors, the majority could not correctly identify all the risk factors. Similarly, many studies from developing African and Middle Eastern countries reported a lack of knowledge of CVD risk factors $[3,12-14]$. The majority (60\%) of a sub-study with the Omani population had low knowledge scores related to the CVD risk factors [15]. In the United States, of 1,702 participants, half had adequate knowledge of CVD. The questionnaire asked the sample to identify 7 risk factors for CVD, and $37 \%$ of the group who responded correctly, identified all seven risk factors, with a mean of 4.9 risk factors [15].

In the current study, the majority (87.6\%) indicated chest pain or discomfort as the most prominent symptom, higher than reported in studies from Kuwait and Saudi Arabia [2,16]. Being knowledgeable about CVD signs and symptoms is important, supporting early intervention and a better outcome. In Singapore, a delay in an intervention is mostly caused by the patient's inability to recognize the signs and symptoms of myocardial infarction [17]. It is concerning that the majority in the current study were not aware of the CVD symptoms. Similarly, a study revealed that $60 \%$ of the participants could not identify one symptom of myocardial infarction [18].

The current study also assessed the level of knowledge regarding the factors that prevent CVD, not frequently reported in the literature. Though almost all the participants indicated smoking cessation as an indispensable aspect of CVD prevention, a study reported that only half of the sample were aware that smoking cessation is a protective factor for CVD. This difference might be due to differences in the population [19].

The overall level of knowledge related to CVD risk factors was weak. The current study provides a unique assessment method for the level of knowledge related to preventative CVD factors. In addition, the study provided valuable educational material to reinforce knowledge about CVD and the risk factors. The majority of the sample (99\%) indicated that the lecture was beneficial, and increased their knowledge (90.7\%).

\section{Conclusions}

The current study demonstrates a knowledge deficit regarding CVD risk factors, symptoms, management, and the association between each domain. Such knowledge will ensure early presentation to medical attention and improve the outcome. The educational material was beneficial and increased the level of knowledge, especially if social media was used. Additional educational campaigns are required to increase the level of knowledge about CVD. Further studies in different regions of Saudi Arabia are required to estimate the level of knowledge.

\section{Additional Information \\ Disclosures}

Human subjects: Consent was obtained or waived by all participants in this study. King Abdullah International Medical Research Center issued approval SP20/348/J. The above study got an IRB approved for the research proposal, informed consent, and data collection/questionnaire. Animal subjects: All authors have confirmed that this study did not involve animal subjects or tissue. Conflicts of interest: In compliance with the ICMJE uniform disclosure form, all authors declare the following: Payment/services info: All authors have declared that no financial support was received from any organization for the submitted work. Financial relationships: All authors have declared that they have no financial relationships at present or within the previous three years with any organizations that might have an interest in the submitted work. Other relationships: All authors have declared that there are no other relationships or activities that could appear to have influenced the submitted work.

\section{References}

1. Cardiovascular Diseases. (2020). Accessed: June 7, 2020: https://www.who.int/health-topics/cardiovasculardiseases/\#tab=tab_1.

2. Albugami S, Al-Husayni F, Bakhsh L, et al.: Correction: the perception of coronary artery disease and cardiac catheterization in Saudi Arabia: "What the public know". Cureus. 2020, 12:c27. 10.7759/cureus.c27

3. Fahs I, Khalife Z, Malaeb D, Iskandarani M, Salameh P: The prevalence and awareness of cardiovascular diseases risk factors among the Lebanese population: a prospective study comparing urban to rural populations. Cardiol Res Pract. 2017, 2017:3530902. 10.1155/2017/3530902

4. Traina MI, Almahmeed W, Edris A, Tuzcu EM: Coronary heart disease in the Middle East and North Africa: current status and future goals. Curr Atheroscler Rep. 2017, 19:24. 10.1007/s11883-017-0659-9

5. AlHabib KF, Hersi A, AlFaleh H, et al.: Baseline characteristics, management practices, and in-hospital 
outcomes of patients with acute coronary syndromes: results of the Saudi project for assessment of coronary events (SPACE) registry. J Saudi Heart Assoc. 2011, 23:233-239. 10.1016/j.jsha.2011.05.004

6. Mukattash TL, Shara M, Jarab AS, Al-Azzam SI, Almaaytah A, Al Hamarneh YN: Public knowledge and awareness of cardiovascular disease and its risk factors: a cross-sectional study of 1000 Jordanians. Int J Pharm Pract. 2012, 20:367-376. 10.1111/j.2042-7174.2012.00208.x

7. Dokunmu TM, Yakubu OF, Adebayo AH, Olasehinde GI, Chinedu SN: Cardiovascular risk factors in a suburban community in Nigeria. Int J Hypertens. 2018, 2018:6898527. 10.1155/2018/6898527

8. Güneş FE, Bekiroglu N, Imeryuz N, Agirbasli M: Awareness of cardiovascular risk factors among university students in Turkey. Prim Health Care Res Dev. 2019, 20:e127. 10.1017/S146342361900063X

9. Almalki MA, AlJishi MN, Khayat MA, Bokhari HF, Subki AH, Alzahrani AM, Alhejily WA: Population awareness of coronary artery disease risk factors in Jeddah, Saudi Arabia: a cross-sectional study. Int J Gen Med. 2019, 12:63-70. 10.2147/IJGM.S184732

10. Raosoft Sample Size Calculator. (2020). Accessed: June 7, 2020: http://www.raosoft.com/samplesize.html.

11. Al-Baghli NA, Al-Ghamdi AJ, Al-Turki KA, El-Zubaier AG, Al-Mostafa BA, Al-Baghli FA, Al-Ameer MM: Awareness of cardiovascular disease in eastern Saudi Arabia . J Family Community Med. 2010, 17:15-21. 10.4103/1319-1683.68784

12. Boateng D, Wekesah F, Browne JL, et al.: Knowledge and awareness of and perception towards cardiovascular disease risk in sub-Saharan Africa: a systematic review. PLoS One. 2017, 12:e189264. 10.1371/journal.pone.0189264

13. Maksimović MŽ, Marinković JM, Vlajinac HD, Maksimović JM, Tomanić MS, Radak DJ: Awareness and knowledge of cardiovascular disease risk factors among medical students. Wien Klin Wochenschr. 2017, 129:458-463. 10.1007/s00508-017-1192-0

14. Martsevich SY, Semenova YV, Kutishenko NP, Zagrebelnyy AV, Ginzburg ML: Awareness of cardiovascular disease, its risk factors, and its association with attendance at outpatient clinics in acute coronary syndrome patients. Integr Med Res. 2017, 6:240-244. 10.1016/j.imr.2017.06.003

15. Wartak SA, Friderici J, Lotfi A, Verma A, Kleppel R, Naglieri-Prescod D, Rothberg MB: Patients' knowledge of risk and protective factors for cardiovascular disease. Am J Cardiol. 2011, 107:1480-1488. 10.1016/j.amjcard.2011.01.023

16. Awad A, Al-Nafisi H: Public knowledge of cardiovascular disease and its risk factors in Kuwait: a crosssectional survey. BMC Public Health. 2014, 14:1131. 10.1186/1471-2458-14-1131

17. Quah JL, Yap S, Cheah SO, et al.: Knowledge of signs and symptoms of heart attack and stroke among Singapore residents. Biomed Res Int. 2014, 2014:572425. 10.1155/2014/572425

18. Vaidya A, Aryal UR, Krettek A: Cardiovascular health knowledge, attitude and practice/behaviour in an urbanising community of Nepal: a population-based cross-sectional study from Jhaukhel-Duwakot Health Demographic Surveillance Site. BMJ Open. 2013, 3:e002976. 10.1136/bmjopen-2013-002976

19. Ghaddar F, Salameh P, Saleh N, et al.: Noncardiac Lebanese hospitalized adult patients' awareness of their coronary artery disease risk factors. Vasc Health Risk Manag. 2018, 14:371-382. 10.2147/VHRM.S176167 